\title{
Contribution to the methodology of determining the optimum mud density - a case study from the offshore gas condensate field D in the Persian Gulf
}

The Mining-Geology-Petroleum Engineering Bulletin UDC: 622.2

DOI: 10.17794/rgn.2018.4.9

Review professional paper

\author{
Damir Zadravec'; Zdenko Krištafor ${ }^{2}$ \\ ${ }^{1}$ Qatar Petroleum, Al Corniche St, P.O. BOX 3212, Doha Qatar \\ ${ }^{2}$ University of Zagreb, RGN faculty, Pierottijeva 6, Zagreb, Croatia
}

\begin{abstract}
Drilling the wells using water based mud through shale formations, causes their exposure to serious time-dependent wellbore instability due to shale swelling. Operating companies, before drilling operations through demanding shale formations, usually conduct drilling fluid optimization studies in order to define the proper mud type, mud density, salt type and concentration for inhibition. Through the analysis of offset wells, they are interpreting data about mud filtrate breakouts into the rock formations and chemical potential mechanisms to understand their influence on the time-dependent wellbore instability. The main objective of this paper is to give an insight in time-dependent and mechanical wellbore instability problems faced while drilling the wells through different shale formations in the gas condensate field $\mathrm{D}$ in the Persian Gulf. The importance of drilling fluid design optimization and solutions applied to overcome hole instability problems were analysed and highlighted. Besides the development of a model for mud density calculations, a concept of effective hoop stress and its influence on time dependent failure mechanisms is discussed. As a contribution to the method improvement, mud density calculation is verified by taking into the consideration the relationship between pore pressure and effective hoop stress and it is based on measured data from Well A in gas condensate field D from the Persian Gulf.
\end{abstract}

\section{Keywords:}

time-dependent well bore instability, shale formations, effective hoop stress, mud density.

\section{Introduction}

Wellbore drilling operations in a phase foreseen for installation of one of the intermediate casings, generally is considered as the most demanding in the entire wellbore drilling process, as it is, due to inherent complexity, related to the uncertainty in the lithological composition and the petrophysical properties of the rocks (Zadravec, 2012). The causes of such uncertainties are the overpressurized zones in the shales, problems of lost circulation or disturbed wellbore stability due to changes in the mud properties associated with insufficient hole cleaning or mud filtrate penetration into the rock formations. In order to reduce the technical risks such as cavings in a hole, unplanned hole reaming, a stuck pipe or lost pipes in a hole and a consequently longer duration of drilling operations, it is necessary to apply proper drilling parameters for the selected bottom hole assembly, and to determine the optimal density and rheological properties of the mud. This paper will present a review and the consideration of the time-dependent and mechanical wellbore instability difficulties faced while drilling development wells through Gudair, Wara, Mauddud, Burgan,

Corresponding author: Zdenko Krištafor

zdenko.kristafor@rgn.hr
Zubair (shale formations) and argillaceous limestone before reaching the pay zone in gas condensate field D in the Persian Gulf. The case study and method for drilling fluid design optimization applied to overcome wellbore instability problems in shale formations in field $\mathrm{D}$ will be presented and analysed. In addition, as contribution to determining optimal drilling mud density, a concept of effective hoop stress, time dependent failure mechanisms and an optimized mud density calculation that took into consideration the relationship between pore pressure and effective hoop stress with original data from Well $\mathrm{A}$ in gas condensate offshore field $\mathrm{D}$ will be presented. The final result of the drilling fluid optimization study includes precisely determined mud density, salt concentration and salt type recommendation for inhibition of each shale formation and optimised drilling practice to improve entire wellbore stability.

\section{Concepts of the effective stress and time-dependent wellbore instability in shales}

Drilling wells of complex geometry, under high pressure and high temperature conditions, particularly in a demanding deep-sea offshore environment or highly de- 
viated or horizontal extended reach wells, is characterized by the requirement of maintaining equivalent circulating density (ECD) of the mud, sometimes within the narrow limits between pore pressure and fracturing pressure gradients. ECD is the effective density exerted by a circulating fluid against the formation that takes into account the hydrostatic head and the pressure drop in the entire annulus above the point being considered. Furthermore, determining the exact relationship between pore pressure gradient and fracture pressure gradient of the rocks is one of the priorities in understanding the interaction between pay zone rocks and cap rocks. The main purpose of understanding this relationship is a prerequisite for the well design and the optimization of drilling parameters between patterns of the trends in the development of the pore pressure and fracture pressure gradients. The origin of the determination of a safe drilling area, between the mentioned pressure gradients at a certain depth of the well, is prediction of the pore pressure gradient (Zadravec, 2012). Therefore, "the accuracy of its determination is of fundamental importance for casing design, casing setting depth determination, and the prevention of the kicks and blowouts while drilling operations" (Mouchet and Mitchel, 1989). For well design, especially of the exploratory wells in new unknown exploration areas, different methods or models for the prediction of the pore pressure gradient have been developed. Some methods, introduced by Bowers (Bowers, 1994), Eaton (Eaton, 1976), and the "d" exponent method (Jorden and Shirley, 1966), use the data collected during drilling operations and their interpretation indirectly predicts the trend of the change in the pore pressure gradient. The d-exponent method is widely accepted as a method suitable for determining the pore pressure gradient while drilling in shale formations. According to Solano et al. (2007) "the limitation of this method stems from the fact that the trend of normal rock compaction should be interpreted from data collected by geological monitoring and collecting drilling cuttings and thus depends on the skill and experience of field geologists or interpreters". Thus, the data collected is subjected to inaccuracies and prediction errors in the trend of normal rock compaction determination. To reduce the geological uncertainties, calculation methods are developed based on the relationship between effective stress and the "d" exponent for each individual well with the purpose of defining the trend of normal rock compaction for a particular field. This approach implies the knowledge about the petrophysical and geomechanical properties of rocks, and in particular the understanding of stress genesis in rocks through the stress strain relationship, which is also one of the pressure generator (Zadravec, 2012). According to Moss, "the mathematical relationship between in situ rock stress and associated pore pressure is defined by the concept of effective stress" (Moos, 2006). The implicit, "effective stress is a part of the total loads that the rock itself carries" (Moos, 2006).
While drilling with water-based mud in an overbalance condition through shale formations without an effective flow barrier present at the wellbore wall, mud filtrate will penetrate progressively into the rock formation (Tan et al., 1996a). Due to the low permeability of the shale formation that is typically in the range between $10^{-21}$ and $10^{-18} \mathrm{~m}^{2}\left(10^{-9}\right.$ to $10^{-6}$ Darcy) filter cake or effective barrier will not be formed on the wellbore walls. The low filtration rate will result in negligible deposition of drilling fluid solids on the wellbore wall and any solid deposition will be eroded by the hydrodynamic action of the drilling fluid. Due to the water saturation and low permeability of shales, penetration of a small volume of mud filtrate into the formation results in a considerable increase in pore pressure near the wellbore wall. The increase in pore pressure reduces the effective mud support i.e., reduces the acting of mud as a hydrostatic column over pore pressure of the rocks formation at a selected depth, which leads to a less stable wellbore condition. The very fine pores and negative clay charges on pore surfaces lead to shales exhibiting membrane behaviour. Due to the chemical potential mechanism, induced formation water flowing out the shale rocks or mud filtrate flowing into the shale rocks is almost similar to the water flowing through a semi permeable membrane (Tan et al., 2002). The driving force for water transportation in no overbalance conditions due to low mud density and the chemical potential gradient across the membrane, that is generally related to the difference in solute, in this case the salt concentration in the mud. In the case that water activity of the drilling fluid becomes less than the shale activity, an osmotic outflow of pore fluid from the formation will occur through a semipermeable membrane which is permeable for water and not permeable to soluble ions or molecules. Shale rocks exhibit a non-ideal semipermeable membrane behaviour to water-based solutions because it has a range of pore sizes, including wide pore throats, which result in significant permeability to solutes. The wide throats reduce the solute interaction with the pore surfaces, which increases the permeability of the membrane to solutes. The solutes transferred across the membrane system will reduce the chemical potential (water activity) of the pore fluid, which will gradually reduce the chemical potential difference between the drilling fluid and the shale, and consequently will reduce the effective mud support (Qadmani et al., 2009).

In order to optimize proper drilling parameters and mud density, understanding of the concept of effective stress is of high importance. Numerous laboratory tests, theoretical analyses, case studies and considerations have shown that rock properties, such as specific resistance, the rate of sound speed through the rock, the density, the conductivity, the porosity and the mechanical strength, are consequences or functionally depend on the intensity of the effective stress (Moos, 2006). Accordingly, by measuring the aforementioned physical proper- 
ties of shale rocks and by analysing the measured values, in particular the rate of sound speed through the rock and the resistance, it is possible to determine the effective stress. According to Moss et al. (1998) such analyses are the basis for creating algorithms for predicting pore pressure in the rocks. In addition, "the effective stress determines the strength of the faults surfaces, the permeability of the fractures and affects the stability and geometry of the cross section of the well bore" (Schutjens et al., 2004). For example, in areas exposed to large variations in horizontal stresses, (stress which acts perpendicular to the axis of a vertical well), the circular borehole shape takes the shape of an ellipse (see Figure 1), while the cross section of the borehole section increases in the direction of minimal horizontal stress. Under such conditions, cracks in the rock are formed at the edges of the elliptical cross section of the wellbore, enabling mud filtrate breakouts into the rock and enlarging the hole diameter (washouts). By measuring the orientation of the fractures or the increase of the borehole diameter, the direction of the minimal horizontal stress in the observed area and thus the in-situ stress conditions can be determined. An increase in borehole diameter can be determined by using electric wireline measurements (CBIL, FMI or EMI) (Image logs) or by orientated x/y caliper measurement of the borehole diameter. In addition, through the interpretation of electric wireline measurements, it is possible to detect drilling induced fractures, which occur in the direction of the maximal horizontal stress. Fractures induced by the drilling process occur in the rock due to the dynamic conditions while mud circulates through the open hole as the functional requirement of wellbore stability based on the relationship between pore pressure in the rock and hydrostatic pressure of the mud column. Drilling induced fractures and breakouts are occurrences as the result of completely different conditions and stress relations in the wellbore. In the case of drilling induced fractures, the force due to the hydrostatic pressure of the mud is greater than the force due to horizontal stress in the rocks. Growth or elliptical wellbore deformation occurs when the tangential (hoop) stress in the wellbore becomes larger than the shear strength of the rock. By measuring the width of the mentioned breakouts on a rock sample, the maximal horizontal stress can be determined in the nearby wellbore (grooving) zone. In the vertical wellbores, the breakouts are concentrated in the direction of the minimal horizontal stress, because this is an area of action of the maximal tangential (hoop) stress.

Figure 1 shows the characteristic stresses in the nearby zone of the vertical wellbore where the breakouts and the enlargement of the wellbore diameter are oriented in the direction of the minimal horizontal stress $\left(\sigma_{\mathrm{h}}\right)$ and in the direction of the maximal tangential (effective hoop) stress $\left(\sigma_{\mathrm{H}}^{\prime}\right)$ respectively, where:

$\sigma_{\mathrm{H}}-$ Maximal horizontal stress,

$\sigma_{\mathrm{h}}-$ Minimal horizontal stress

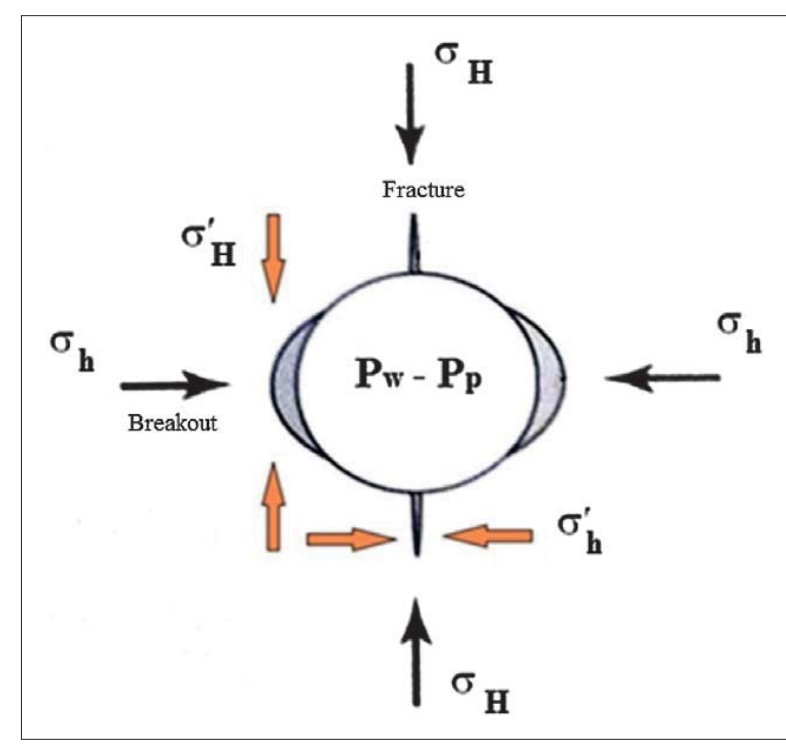

Figure 1: Characteristic stresses in nearby zone of the vertical wellbore

$\sigma_{\mathrm{H}}$ - Maximal tangential (effective hoop) stress;

$\sigma_{\mathrm{h}}{ }^{\prime}$ - Minimal tangential (effective hoop) stress.

If the rock inside area of the breakouts does not have sufficient compressive strength, due to the tangential stress in the nearby zone of the wellbore, it will lead to caving of the tiny rock fragment into the well. Initially, it will be expressed in the form of "splinters" and most often occurs due to mud density that is too low (see Figure 2).

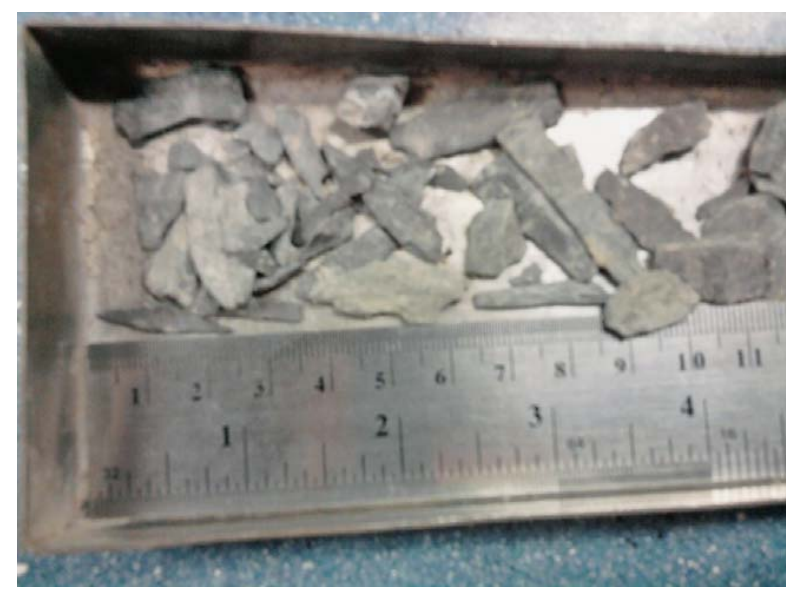

Figure 2: Rock particles cavings in shape of splinters (Zadravec, 2012)

Broken rock fragments in the areas of breakouts due to the maximal tangential stress after the initial sagging in the form of splinters, took the shape of tubes (see Figure 3) or polyhedral angular (see Figure 4). They have a visible conjugated shear surface which is the result of the rock fracturing due to shear stress. The above-mentioned peeling can be detected during sampling of the 


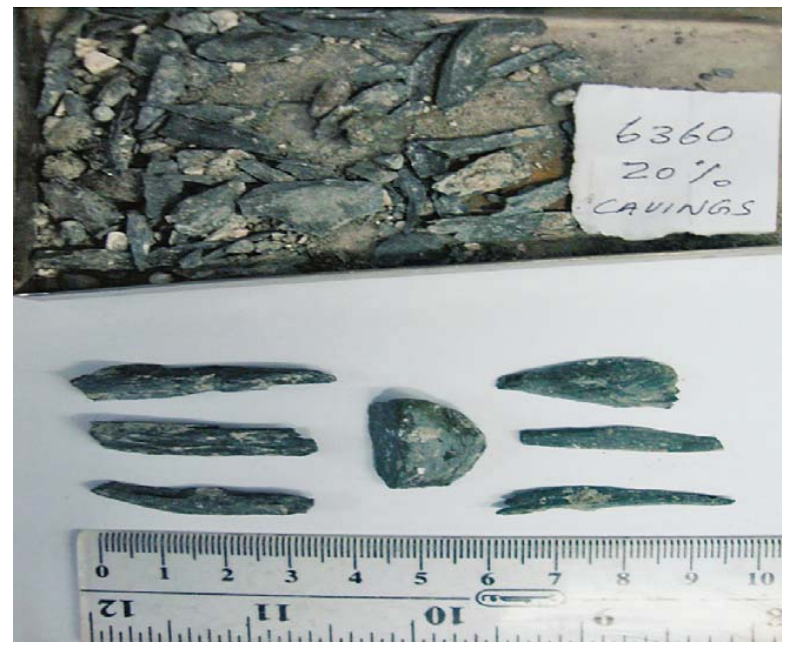

Figure 3: Rock particles cavings in shape of tubes (Zadravec, 2012)

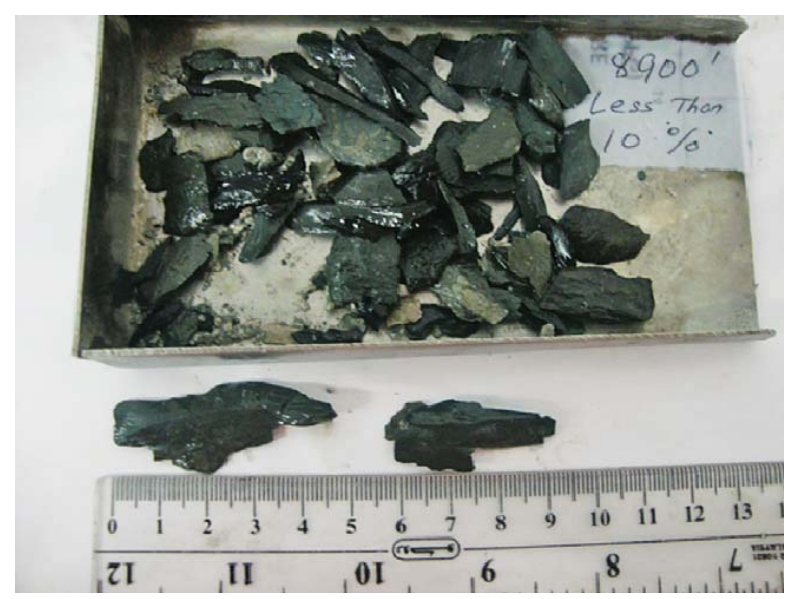

Figure 4: Rock particles cavings in shape of angulars (Zadravec, 2012)

drilling cuttings and by electrical wireline logging of the diameter of the wellbore (caliper logs) and previously mentioned image logs.

Furthermore, rock fragments due to peeling can have an irregular polyhedral form with one or more clearly expressed tabulars. The mentioned cracking occurs due to the low strength of the contact surfaces between the layers or the cleavage of the existing fractures. Finally, it can be concluded from the aforementioned points that wellbore stability is a function of the drilling mud density, the effective wellbore cleaning and cavings resulting from peeling in the areas of the greatest tangential stress.

\section{Drilling fluid optimization research for gas condensate offshore field D}

Very often, in worldwide drilling operations, difficulties are faced while drilling especially highly deviated or horizontal wells through shale formations before reaching pay zones. According to Qadmani et al. (2009), similar problems were described, and difficulties were highlighted after drilling development wells in offshore Khafji and Dorra fields in the ex-neutral zone between Kuwait and Saudi Arabia in the Persian Gulf. These wells intersect various shale formations and "severe time-dependent wellbore instability problems due to shale sloughing were experienced" (Qadmani et al., 2009). While drilling a $0.311 \mathrm{~m}$ (12 1/4") section of hole, on several wells, tools were held up due to the presence of ledges, different shale formations failed due to insufficient mud density, severe tight spots, overpulls and pack-offs occurred while tripping due to excessive cavings into the wellbore which required hard back reaming and led to inadequate hole cleaning, high torque and dynamic pressure increments. These problems have led to several stuck pipes and drilling sidetracks from the original wells. Qadmani et al. stated that "wellbore instability was attributed to insufficient salinity in the drilling fluid which resulted in pore pressure increase due to the mud filtrate penetration mechanism being not adequately counteracted by the chemical potential mechanism" (Qadmani et al., 2009). As a direct consequence, the pore pressure increased in the nearby wellbore wall area, which reduced the effective mud support, increased ineffective hoop stress and led to unstable wellbore conditions. The same phenomenon is not new, and it was detected while drilling through shale formations with water-based mud in numerous oil and gas fields in the Persian Gulf and worldwide (Last et al., 1995).

To overcome problems with wellbore instability in gas condensate offshore field $\mathrm{D}$, research and a drilling fluid optimization study was performed based on highly deviated and horizontal well data collected while drilling in the field (area of interest) prior to commencement of the drilling operations on new infill wells. The main goal of the study was to evaluate the potential of timedependent wellbore instability mechanism(s) in Gudair, Wara, Mauddud, Burgan and Zubair shales and across argillaceous limestone, to determine the appropriate mud properties for drilling new infill wells, salt type and concentration, and to develop a solution and strategy to mitigate and/or manage wellbore instability. The optimal drilling mud design, in terms of mud density and type, salt type and concentration, has been developed based on mud logging data, drilling cutting samples collected and cores taken at the critical formations of interest on numerous offset wells drilled in the field with different levels of success. Wellbore stability analysis was subsequently based on the building of the Mechanical Earth Model (MEM) in order to develop the safe mud weight window and recommend drilling mud weight and inhibition for planned wells intervals. The MEM of the wells was developed (curtain-sectioned) from offset wells data based on the prognosis of formation tops and 
Table 1: Recommended mud density and salinity for proposed mud (Mohiuddin et al., 2010)

\begin{tabular}{|l|l|l|l|}
\hline Depth $(\mathbf{m})$ & Shale formation & $\begin{array}{l}\text { Recommended mud } \\
\text { density }\left(\mathbf{k g} / \mathbf{m}^{3}\right)\end{array}$ & $\begin{array}{l}\text { Recommended salt } \\
\text { Concentration } \\
(\% \mathbf{~ N a C l})\end{array}$ \\
\hline $1611-1641$ & Gudair & 1230 & 6 \\
\hline $1769-1815$ & Wara & 1380 & 7.5 \\
\hline $1816-1823$ & Mauddud & 1380 & 9 \\
\hline $1844-1942$ & Burgan & 1460 & 9 \\
\hline $2233-2355$ & Zubair & 1490 & 19 \\
\hline $2360-2454$ & Argillaceous Lhst & 1490 & 15 \\
\hline
\end{tabular}

the trajectories of the new planned infill wells, where offset wells were also used to cross check the developed model. The MEM contains data for unconfined compressive strength (UCS) of the rocks, tensile failure, wide breakouts and breakdowns based on caliper logs, information about mud losses and upper and lower mud weight margin for new infill wells in the offshore oil field. The theoretical background for developing the MEM was a reflection on the fact that, according to Tan and group of authors, the "occurrence of time-dependent wellbore instability is largely attributed to the increasing of pore pressure in the rock formation with time, due to mud pressure penetration mechanism" (Tan et al., 1996b). Initially for building the MEM, it is important to understand the local geology, type, genesis and petrophysical properties of the rocks in the field. Based on this knowledge, a detailed laboratory analysis and in situ measurement led to developing profiles of elastic and rock-strength parameters including unconfined compressive strength (UCS). These parameters are important to predict pore pressure gradients, minimal $\left(\sigma_{h}\right)$ and maximal horizontal stresses $\left(\sigma_{\mathrm{H}}\right)$ which can be identified and measured in the drilling phase and vertical stress, $\left(\sigma_{\mathrm{V}}\right)$. Finally, determining intensity and horizontal stress direction is important for proper drilling parameters and drilling mud density optimization (Ali et al., 2003), which will be described in more detail further on in this paper.

The pore pressure increase will lead to a decrease in the effective mud support on the wellbore wall and possibly swelling/generation of hydration stress with time in the formation (Tan et al., 1997) which will both result in less stable wellbore walls. Hence, to avoid time-dependent wellbore instability, the water activity of the drilling fluid needs to be sufficiently low (i.e. drilling fluid should contain a sufficiently high salt concentration) to induce the required osmotic flow from the formation to the borehole (chemical potential mechanism) to counteract the pore pressure increase due to mud filtrate penetration (Tan et al., 1996a). During the preparation of drilling fluid design, optimization was done for different shale formations for several new infill wells and both mud pressure penetration and chemical potential mechanisms have been taken into consideration. The information required and used in the analysis included the shale (rock) genesis and mineral composition, petrophysical properties, drilling fluid properties, overbalance pressure, formation temperature, mud density which will induce breakouts and mud weight used while drilling offset wells in the field (Mohiuddin et al., 2010). The analysis and optimizations were based on properties for proposed water based mud. The estimated mud filtrate adhesion (Amf) was $0.0386 \mathrm{~N} / \mathrm{m}$ (38.6 dyne/ $\mathrm{cm}$ ) and membrane efficiency was $26.8-39.5 \%$. A temperature gradient used in the analysis was $3.88^{\circ} \mathrm{C} / 100 \mathrm{~m}$. The depths for different shale formations for a new infill well were mapped and correlated with the corresponding depths from offset wells. The recommended mud weight for a $0.311 \mathrm{~m}$ (12 1/4") hole section for mechanical wellbore stability was used together with the formation pressure gradient to determine the overbalance pressures and gradients for the planned well. The main target of the optimization study was to manage generated overbalance pressure that will result in a pore pressure increase due to the mud pressure penetration mechanism which, ideally, should be counteracted by the chemical potential mechanism. Mud weights for drilling through the mentioned different shale formations of new infill wells were optimized based on the validated design criteria for net mud weight reduction as a percentage up to $10 \%$ of breakout mud weight versus hole enlargement (due to formation breakouts). Input data were collected by running a caliper and FMI logs on offset wells in the field and by mapping and analysing the multiple drilling events such as tight hole, overpulls, torque increase, pack off, back reaming, reaming down, etc. Additionally, pore pressure changes due to mud pressure penetration and chemical potential mechanisms were laboratory measured on the cores, and after 7 days of exposure, based on the measured rock properties for the selected shale formations, drilling mud properties and overbalance pressure were determined (Mohiuddin et al., 2010). The final result of the drilling mud optimization study was precisely determined mud density, salt concentration and salt type recommendation for inhibition of each shale formation (see Table 1), with the corresponding measured depth based on the well trajectory plan for the selected new infill well. The key components optimised for the proposed mud were: shale hydration suppressant, dispersion inhibitor i.e., encapsulator, 
sealing additive, anti - accrete and ROP enhancer. It is important to remember that the proposed data is only valid for the selected well as the mud salinity is dependent on the recommended mud weight and formation pressure gradient which may be different for the other planned wells.

In addition to the recommended mud density and salinity for the proposed mud, the following set of recommendations for proper drilling practice were attributed to minimize the potential drilling hazards (Mohiuddin et al., 2010):

- Great attention should be paid on proper hole cleaning while drilling (application of optimum flow rate, rotary speed, mud rheology and drill string reciprocation) to avoid tight hole, packing off and bottom hole assembly or casing string differential sticking.

- Use stable geometry bottom-hole assembly to minimize dynamic impact on the wellbore wall.

- Using mud with good sealing capacity, e.g. containing asphaltene with a wide range of particle size distribution and strengthening materials, since micro-fractures are likely to be generated due to rock failure.

- Monitor ECD for swab effect while reciprocating pipe off bottom, and while tripping.

- Closely monitor any increase in drag that could be an indication of wellbore walls condition deterioration or mechanical caving based on improper drilling parameters or practice.

- Monitor ECD trend for signs of annular loading, pump pressure and hook load/drag that could indicate wellbore walls condition deterioration.

- Use annular pressure-while-drilling measurements to monitor and to verify the ECD while drilling.

- Conduct a wiper trip every 24 hrs or after drilling every 5 or 6 stands to clean the hole, whichever comes first.

\section{Calculation method for optimal drilling mud density determination}

Mud density should not be determined or optimized solely to satisfy the condition of the hydrostatic pressure overbalance at a certain depth, but also due to maintaining the well bore stability. Apart from the overburden pressure (geostatic pressure), fracturing pressure and maximal and minimal horizontal stresses, which may vary to the equivalent circulating density of the mud (ECD) value of 1600 to $3900 \mathrm{~kg} / \mathrm{m}^{3}$ (Moos, 2006), the calculations take into consideration the unconfined compressive strength of the rock (UCS), which is denoted as $\mathrm{F}$ in Equation 1. Unconfined compressive strength of the rock depends on the mineral composition, i.e. the type of rock and the burial depth, and has the value for different rocks in a range from 6.9 $\mathrm{MPa}$ to $172 \mathrm{MPa}$ (Moos,
2006). Determining the required mud density for wellbore drilling is of the utmost importance for primary well control, preservation of wellbore stability and it can be calculated from hydrostatic pressure of a mud column from Mohr-Coulomb's elasticity Equation 1 (Last et al., 1995):

$$
P_{W}=\frac{\left(\left(3 \cdot \sigma_{H}-\sigma_{h}\right)-F-(1-N) \cdot P_{P}\right)}{(1+N)}
$$

Where:

$\mathrm{P}_{\mathrm{W}}-$ Hydrostatic pressure of mud column (MPa),

$\sigma_{\mathrm{H}}-$ Maximal horizontal stress (MPa),

$\sigma_{\mathrm{h}}-$ Minimal horizontal stress (MPa),

$\mathrm{F}$ - Unconfined compressive strength of the rock (MPa),

$\mathrm{N}$ - constant determined by the internal friction angle as a function of the rock type;

$\mathrm{P}_{\mathrm{p}}$ - pore pressure $(\mathrm{MPa})$.

Mud density also affects the rate of penetration and it is therefore very important that it is not too high but it must be exactly defined in accordance with the functional requirements of the wellbore stability. In case of excessive mud density, induced fractures occur in the direction of the action of the maximal horizontal stress, and in contrast to, in the case that the mud density is too low for drilling, induced breakouts and cavings of the rock fragments into the wellbore will occur, in the direction of the minimal horizontal stress. From the above, it is apparent that the hydrostatic pressure of the mud column needs to achieve a precise pressure (mud window) within the wellbore to avoid induced breakouts and a pressure at which no induced fracture in the rock will occur.

The calculations that describe the determination of the required mud density in accordance to the measured field data from the well in gas condensate field D in the Persian Gulf in order to satisfy the mentioned wellbore stability condition uses the actual input data (Zadravec, 2012) as follows:

- Vertical depth (TVD): $3050 \mathrm{~m}$;

- Overburden pressure gradient (vertical stress): $0.0226 \mathrm{MPa} / \mathrm{m}$;

- Maximal horizontal pressure gradient: 0.0181 $\mathrm{MPa} / \mathrm{m}$;

- Minimal horizontal pressure gradient: 0.0158 $\mathrm{MPa} / \mathrm{m}$;

- Pore pressure gradient: $0.0113 \mathrm{MPa} / \mathrm{m}$;

- Unconfined compressive strength of the rock (UCS): $\mathrm{F}=34.48 \mathrm{MPa}$;

- For Internal friction angle of $30^{\circ}$, constant determined depending on the rock type is $\mathrm{N}=3$.

The main task is to define mud column hydrostatic pressure i.e. equivalent mud density, which needs to be precisely optimized to avoid breakouts and tensile failure in vertical well and especially in horizontal well, which is parallel to minimal horizontal stress. 
For vertical well is valid as follows:

- Pore pressure at the depth of $3050 \mathrm{~m}$ with pore pressure gradient of $0.0113 \mathrm{MPa} / \mathrm{m}$ is $34.47 \mathrm{MPa}$.

- Maximal horizontal stress $\sigma_{\mathrm{H}}$ reduced for the value of pore pressure at the depth of $3050 \mathrm{~m}$ with pressure gradient of $0.0181 \mathrm{MPa} / \mathrm{m}$ is: $55.21-34.47=$ $20.74 \mathrm{MPa}$.

- Minimal horizontal stress $\sigma_{\mathrm{h}}$ reduced for the value of pore pressure at the depth of $3050 \mathrm{~m}$ with pressure gradient of $0.0158 \mathrm{MPa} / \mathrm{m}$ is: $48.19-34.47=$ $13.72 \mathrm{MPa}$.

- Evaluation of the minimal and maximal horizontal stress is according to Mohr - Coulomb elasticity Equation 1.

Taking into consideration only tangential (effective hoop) stress, where $P_{W}$ is calculated hydrostatic pressure of the mud column (MPa) and $P_{P}$ is pore pressure (MPa), follows the proposed solution:

Initially, maximal and minimal effective hoop stresses need to be calculated:

Maximal tangential (effective hoop) stress $\left(\sigma_{\mathrm{H}}{ }_{\mathrm{H}}\right.$ :

$$
\begin{gathered}
\sigma_{H}^{\prime}=3 \cdot \sigma_{H}^{\prime}-\sigma_{H}^{\prime}-\left(P_{W}-P_{P}\right) \\
\sigma_{H}^{\prime}=3 \sigma_{H}^{\prime}-\sigma_{H}^{\prime}-\left(P_{W}-P_{P}\right)= \\
=(3 \cdot 20.74)-13.72-\left(P_{W}-34.47\right)=48.5-\left(P_{W}-34.47\right)
\end{gathered}
$$

Minimal tangential (effective hoop) stresses $\left(\sigma^{\prime}{ }_{\mathrm{h}}\right.$ ):

$$
\begin{gathered}
\sigma_{h}^{\prime}=3 \sigma_{h}^{\prime}-\sigma_{H}^{\prime}-\left(P_{W}-P_{P}\right) \\
\sigma_{h}^{\prime}=3 \sigma_{h}^{\prime}-\sigma^{\prime}{ }_{H}-\left(P_{W}-P_{P}\right)= \\
=(3 \cdot 13.72)-20.74-\left(P_{W}-34.47\right)=20.42-\left(P_{W}-34.47\right)
\end{gathered}
$$

According to stability requirements:

$$
\sigma_{H}^{\prime}-N \cdot \sigma_{h}^{\prime}>\mathrm{F}
$$

and

$$
\sigma_{h}>0
$$

follows:

$$
\begin{gathered}
\sigma_{H}^{\prime}-N \cdot \sigma_{h}^{\prime}>\mathrm{F}=48.5-\left(P_{w}-34.47\right)- \\
-3 \cdot\left(P_{w}-34.47\right)>34.48 \mathrm{MPa} \Rightarrow P_{w}>37.92 \mathrm{MPa} . \\
48.50-(37.92-34.47)-3 \cdot(37.92-34.47)= \\
=45.05-10.35=34.70>34.48 \mathrm{MPa} .
\end{gathered}
$$

With hydrostatic pressure of the mud column of 37.92 $\mathrm{MPa}$, maximal tangential (effective hoop) stress is:

$$
48.5-\left(P_{w}-34.47\right)=48.5-(37.92-34.47)=45.05 \mathrm{MPa} \text {. }
$$

Minimal tangential (effective hoop) stress with hydrostatic pressure of the mud column of $37.92 \mathrm{MPa}$ is:

$20.74-\left(P_{w}-34.47\right)=20.74-(37.92-34.47)=16.97 \mathrm{MPa}$.

Therefore, in order to avoid drilling induced breakouts due to insufficient mud density, it is mandatory to maintain hydrostatic pressure of the mud column inside the wellbore of $37.92 \mathrm{MPa}$, which at depth of $3050 \mathrm{~m}$ corresponds with equivalent mud density of $1267 \mathrm{~kg} / \mathrm{m}^{3}$.

To avoid formation fracturing the difference between the minimal tangential (effective hoop) stress and the difference between hydrostatic pressure of the mud and the pore pressure in the well must be greater than 0 ;

$$
16.97-\left(P_{w}-34.47\right)>0, \Rightarrow P_{w}<51.44 \mathrm{MPa} \text {. }
$$

Hydrostatic pressure of a mud column that is higher than 51.44 MPa will result in formation fracturing and mud losses, which at a depth of $3050 \mathrm{~m}$ corresponds to the equivalent mud density of $1719 \mathrm{~kg} / \mathrm{m}^{3}$.

For a horizontal well, in order to avoid drilling induced breakouts, it is necessary to meet the same initial condition as required for vertical well:

$$
\sigma_{H}^{\prime}-N \cdot \sigma_{h}^{\prime}>\mathrm{F}
$$

Maximal vertical stress $\left(\sigma^{\prime}{ }_{\mathrm{v}}\right)$ :

$$
\sigma_{V}^{\prime}=\sigma_{G}-P_{P}
$$

where:

$\sigma_{\mathrm{G}}-$ overburden pressure (MPa),

$\mathrm{P}_{\mathrm{P}}$ - pore pressure $(\mathrm{MPa})$.

Maximal vertical stress $\left(\sigma^{\prime}{ }_{\mathrm{v}}\right)$ at the depth of $3050 \mathrm{~m}$ with overburden pressure gradient of $0.0226 \mathrm{MPa} / \mathrm{m}$ is:

$$
68.93-34.47=34.46 \mathrm{MPa} \text {. }
$$

Maximal horizontal stress $\left(\sigma_{H}\right)$ reduced for the value of pore pressure at the depth of $3050 \mathrm{~m}$ with pressure gradient of $0.0181 \mathrm{MPa} / \mathrm{m}$ is:

$$
55.21-34.47=20.74 \mathrm{MPa} \text {. }
$$

Maximal tangential (effective hoop) stress $\left(\sigma_{H}^{\prime}\right)$ for horizontal well is:

$$
\sigma_{H}{ }_{H}=3 \cdot \sigma^{\prime}{ }_{V}-\sigma_{H}-\left(P_{W}-P_{P}\right)
$$

$$
\begin{aligned}
\sigma_{H}^{\prime} & =3 \cdot \sigma^{\prime}{ }_{V}-\sigma_{H}-\left(P_{W}-P_{P}\right)=(3 \cdot 34.46)-20.74- \\
& -\left(P_{W}-34.47\right)=82.64-\left(P_{W}-34.47\right) M P a
\end{aligned}
$$

From stability requirements follows:

$$
\begin{gathered}
82.64-\left(P_{w}-34.47\right)-3 \cdot\left(P_{w}-34.47\right)>34.48 \mathrm{MPa} \Rightarrow \\
\Rightarrow P_{w}>46.60 \mathrm{MPa} \\
82.64-(46.50-34.47)-3 \cdot(46.50-34.47)= \\
=70.61-36.09=34.52 \mathrm{MPa}>34.48 \mathrm{MPa} .
\end{gathered}
$$

At hydrostatic pressure of a mud column of 46.60 $\mathrm{MPa}$ at a depth of $3050 \mathrm{~m}$, the equivalent mud density is $1537 \mathrm{~kg} / \mathrm{m}^{3}$, which is the minimal mud density to be achieved in order to avoid drilling induced breakouts and peeling of the rock fragments into the wellbore.

Furthermore, in order to avoid the generation of drilling induced fractures in the horizontal well it is necessary to satisfy the condition that minimal tangential (effective hoop) stress must be greater than zero: $\sigma_{h}^{\prime}>0$. 
Minimal tangential (effective hoop) stress $\left(\sigma_{h}{ }_{h}\right)$ for horizontal well is:

$$
\begin{gathered}
\sigma_{h}^{\prime}=3 \cdot \sigma_{H}-\sigma_{V}^{\prime}-\left(P_{W}-P_{P}\right) \\
\sigma_{h}^{\prime}=3 \cdot \sigma_{H}-\sigma_{V}^{\prime}-\left(P_{W}-P_{P}\right)=(3 \cdot 20.74)-34.46- \\
-\left(P_{W}-34.47\right)=27.76-\left(P_{W}-34.47\right) \mathrm{MPa}
\end{gathered}
$$

$P_{w}<62.22 \mathrm{MPa} \Rightarrow 27.76-(62.22-34.47)=0.01 \mathrm{MPa},>0$.

At hydrostatic pressure of a mud column which is greater than 62.22 MPa, formation fracturing and mud losses will occur, which at a depth of $3050 \mathrm{~m}$ corresponds to a mud density of $2074 \mathrm{~kg} / \mathrm{m}^{3}$.

\section{Conclusion}

A case study presented in this paper showed implications of wellbore instability while drilling through shale formations with water based mud on the duration of drilling operations, created lost time and possible effective solutions to fulfil requirements for well bore stability. According to the presented theoretical analysis, determination and quantification of the mechanism of wellbore instability requires knowledge and understanding of several complex facts, such as: identification of magnitude and direction of minimal and maximal horizontal stresses, pore pressure, fracturing pressure and overburden pressure gradients (in-situ stress), induced effective hoop stress around the wellbore, rock properties as UCS and internal friction angle, mineral composition of the rocks and determination of failure criteria. An important (advantage) is that all of the mentioned features and properties could be identified and measured while drilling operations (pore pressure gradient determination by "d" exponent or other applicable methods, derived fracturing gradient determination by FIT or LOT, minimal and maximal horizontal stresses quantification by FIT and verification by caliper logs, core analysis for the determination of UCS and the internal friction angle), and in addition, numerous field based drilling mud properties analyses and optimizations are available, which can be verified later on, confirmed or optimized by laboratory measurements and analysis. Related to the specific case study of wellbore instability in different shale formations in offshore field D in the Persian Gulf, problems while drilling arose due to the insufficient salinity of drilling mud, which resulted in pore pressure increment since the mud pressure penetration mechanism was not counteracted by the proper chemical potential mechanism.

As a contribution to determining the drilling mud density, this paper explicitly shows the sequence of the calculation method for optimum mud density taking into consideration the acting of the effective stress on the well bore stability and the method of their determination. The improved calculating method took into consideration only tangential (effective hoop) stress. A pro- posed solution for vertical wells calculated hydrostatic pressure of the mud column inside the wellbore which will not induce breakouts due to insufficient mud density. In addition, for vertical wells, calculations showed that to avoid formation fracturing, the difference between the minimal tangential (effective hoop) stress and the difference between hydrostatic pressure of the mud and the pore pressure in the well must be greater than 0 . For horizontal wells, to avoid the generation of drilling induced fractures, it is necessary to satisfy the condition that the minimal effective hoop stress must be greater than zero: $\sigma_{\mathrm{h}}>0$

In addition, it was shown that the drilling mud density (mud weight) should not be optimized (determined) solely to satisfy the condition that the hydrostatic pressure of the mud column must be greater than or equal to the value of the formation pore pressure at a certain depth, but also complying with maintaining the well bore stability.

Finally, the following conclusions can be drawn from the post drilling well analysis which were related to the drilling fluid optimization study and drilling practice applied in the new infill well A in the Persian Gulf.

In terms of moderately low water activity of the shale formations and relatively low overbalance pressure, an optimum drilling fluid design for selected mud, whereby the mud filtrate penetration was fully counteracted by the chemical potential mechanism, was very successfully developed for different shale formations in the newly drilled infill well A and together with the application of the presented recommended optimal drilling parameters for certain lithology and strengthening materials kept them stable through drilling operations. There was no non-productive time associated to the wellbore instability in shale formations, no stuck pipe incidents, no loss circulations occurred, electrical wire line logging was completed and multi days MDT logging and the fluid sampling program were successfully conducted with intermittent wiper trips in between. A $0.244 \mathrm{~m}$ (9 $5 / 8$ ") casing was run and cemented successfully with significant time saving and appreciation from the Operating Company Management.

\section{References}

Ali, A., Brown, T., Delgado, R., Lee, D., Plumb, D., Smirnov, N., Marsden, R., Prado-Velarde, E., Ramsey, L., Spooner, D., Stone, T. and Stouffer, T. (2003): Watching rocks change - mechanical Earth modelling. Oilfield Review, $15,22-39$.

Bowers, G. L. (1994): Pore pressure information from velocity data: accounting for overpressure mechanisms besides compaction. SPE Drilling \& Completion, 10, 2, 89-95, Dallas.

Eaton, B. A. (1976): Graphical method predicts geopressures worldwide. World Oil, 183, 1, 100-104, Houston.

Jorden, J. R. and Shirley, O. J. (1966): Application of drilling performance data to overpressure detection. J. Petroleum Technology, 1387-1394. 
Last, N., Plumb, R., Harkness, R., Charlez, P., Alsen and McLean, M. (1995): An integrated approach to evaluating and managing wellbore instability in the Cusiana Field, Colombia, South America. SPE Annual Technical Conference and Exhibition, 22-25 October 1995, 147-160, Dallas.

Mohiuddin, M.A., Povstyanova, M., Maolin, L., Tan, C.P. and Abd Rahim, M. H. (2010): Drilling Fluid Optimization Study on Horizontal Wells in Khafji Field - Phase III. Schlumberger Data and Consulting Services, Al-Khobar, Saudi Arabia.

Moos, D. (2006): Geomechanics applied to drilling engineering. U: Mitchell, R. F. (Ed.): Petroleum engineering handbook: Vol. II Drilling engineering. Society of Petroleum Engineers, II-1-II-87, Richardson.

Moos, D. and Chang, C. (1998): Relationship between porosity, pressure and velocities in unconsolidated sands. Overpressure in petroleum exploration: workshop proceedings, April 7th-8th 1998, Pau.

Mouchet, J. P. and Mitchel, A. (1989): Abnormal pressures while drilling: origins, prediction, detection, evaluation. Elf Aquitaine Editions, 264 p., Boussens.

Qadmani, M. A., Mohiuddin, M. A., Kumamoto, K., Tan and C. P. Povstyanova, M. (2009): Field-based drilling fluid design optimization methodology successfully mitigated time-dependent shale instability in Khafji Field. International Petroleum Technology Conference, 7-9 December 2009, 1-15, Doha.

Schutjens, P. M. T. M., Hanssen, T. H., Hettema, M. H. H., Merour, J., De Bree, P., Coremans, J. W. A. and Helliesen, G.(2004):Compaction-induced porosity/permeability reduction in sandstone reservoirs: data and model for elasticity-dominated deformation. SPE Reservoir Evaluation \& Engineering, 7, 3, 202-216.

Solano, Y. S., Uribe, R., Frydman, M., Saavedra, N. F. and Calderon, Z. H. (2007). A modified approach to predict pore pressure. CT\&F - Ciencia, Tecnologia y Futuro, 3, 3, 103-111.

Tan, C.P., Richards, B.G and Rahman, S.S. (1996a): Managing Physico - Chemical Wellbore Instability in Shales with the Chemical Potential Mechanism. Asia Pacific Oil and Gas Conf., Adelaide, 107-116.

Tan, C.P., Richards, B.G., Rahman, S.S. and Andika, R. (1997): Effects of Swelling and Hydrational Stress in Shales on Wellbore Stability. Asia Pacific Oil and Gas
Conference and Exhibition, Kuala Lumpur, Malaysia, 345-349.

Tan, C.P., Wu, B., Mody, F.K. and Tare, U.A. (2002): Development and Laboratory Verification of High Membrane Efficiency Water-Based Drilling Fluids with Oil-Based Drilling Fluid-Like Performance in Shale Stabilization. OilRock 2-2, Irving, Texas, USA. SPE/ISRM Rock Mechanic Conference, 20 - 23 October, Conference paper, 12 p.

Tan, C.P., Zeynaly-Andabily, M.E. and Rahman, S.S. (1996b): A Novel Method of Screening Drilling Muds against Mud Pressure Penetration for Effective Borehole Wall Support. IADC/SPE Asia Pacific Drilling Technology Conf., Kuala Lumpur, Malaysia, 287-294.

Zadravec, D. (2012): Stochastic model of dynamic system for wellbore drilling. Doctoral thesis. University of Zagreb, Faculty of Mining, Geology and Petroleum Engineering, 174 p. (In Croatian)

\section{NOMENCLATURE}

\section{List of Symbols and Units}

$\sigma_{\mathrm{G}}-$ overburden pressure (MPa)

$\sigma_{\mathrm{H}}-$ Maximal horizontal stress (MPa)

$\sigma_{\mathrm{h}}-$ Minimal horizontal stress (MPa)

$\sigma_{\mathrm{H}}-$ Maximal tangential (effective hoop) stress (MPa)

$\sigma_{\mathrm{h}}$ - Minimal tangential (effective hoop) stress (MPa)

$\sigma_{\mathrm{v}}^{\prime}-$ Maximal vertical stress (MPa)

$\rho-$ mud density $\left(\mathrm{kg} / \mathrm{m}^{3}\right)$

$\mathrm{F}$ - Unconfined compressive strength of rock (MPa)

$\mathrm{N}$ - Internal friction angle

$P_{w}-$ mud hydrostatic column pressure (MPa)

$P_{p} \quad$ - pore pressure $(\mathrm{MPa})$

\section{List of abbreviations}

CBIL - circumferential borehole imaging log - (Baker Hughes)

ECD - equivalent circulating density

EMI - electrical micro imaging - (Halliburton)

FIT - formation integrity test

FMI - formation micro imager - (Schlumberger)

LOT - leak - off test

MDT - modular dynamic tester - (Schlumberger).

MEM - mechanical earth model

UCS - unconfined compressive strength 